Scientific Paper

\title{
Using X-ray diffraction in characterization of bone remodeling and nanocomposites in ovariectomized rats osteopenia model
}

\author{
Nazar KOSTYSHYNa, Mechyslav GZHEGOTSKYIa , Liubov KOSTYSHYN ${ }^{b}$, Oksana YAROVA , Yuriy KULYK ${ }^{d}$, Stepan \\ MUDRYd \\ ${ }^{a}$ Department of Normal Physiology, Danylo Halytsky Lviv National Medical University - Lviv, Ukraine \\ ${ }^{b}$ Department of Toxicological and Analytical Chemistry Danylo Halytsky Lviv National Medical University - Lviv, Ukraine \\ ${ }^{c}$ Department of Theoretical and Applied Statistics - Lviv, Ukraine \\ ${ }^{d}$ Department of Metal Physics, Ivan Franko National University - Lviv, Ukraine \\ *E-mail address: kostyshyn.nm@gmail.com
}

\begin{abstract}
Sedentary lifestyle and physiological menopause are among the risk factors of osteopenia, especially in elderly people. However, bone mineral density decrease can also be observed in young individuals, for instance, due to deficiency of female sex hormones after surgical interventions, particularly ovariectomy. Our research enabled us to assess the efficacy of whole-body vibration in preventing the loss of bone mineral density in the ovariectomy rat osteopenia model. Thus, whole-body vibration with acceleration level $0.3 \mathrm{~g}$ and frequency $50 \mathrm{~Hz}$ was used on young female rats, which had been subjected to ovariectomy $(n=18)$. It had been conducted for 24 weeks, exposure time -30 minutes per day, 5 times a week. Assessment of mineral component loss of the tibia was performed by means of $\mathrm{X}$-ray diffraction. Bone remodeling was assessed by determining hormones: parathyroid hormone and calcitonin, $\mathrm{Ca}$ and $\mathrm{P}$ in the blood. $\mathrm{X}$-ray diffraction is an effective method, which enables the evaluation a nanocomposites structure of the bone tissue in the experiment. In the article, we applied this method to determine the loss of bone mineral mass after ovariectomy and the impact of wholebody vibration under such conditions. In the ovariectomy group, the volume of a mineral component significantly decreased starting already from the 16 th week $(\mathrm{p}<0.05)$ versus control. However, in the group with ovariectomy + wholebody vibration, the loss of a mineral component was insignificant during 8-16 weeks of the investigation, compared with the control group. On the 24th day, the spectrums almost did not differ from ovariectomized rats group. Meanwhile, hormone levels changed in ovariectomized rats group. It should be emphasized that the aforementioned whole-body vibration parameters do not cause severe bone damage or further negative consequences.
\end{abstract}

Key words: whole-body vibration; bone remodelling; bone mineral density; osteoporosis; bone nanocomposites; X-ray diffraction.

\section{Introduction}

Currently, osteoporosis has become a social and economic problem considering the increasing number of an aging population on the planet. ${ }^{1-4}$ Deficiency of female sex hormones is the key cause of the loss of bone mineral density. However, estrogen deficiency is also often observed in women of various ages, especially after ovariectomy. ${ }^{5-7}$ Some investigations indicate that influence of mechanical stimuli intensifies physiological reactions of bone adaptation in different age periods. ${ }^{8-10}$ Accordingly, using mechanical influences on the bone slows down remodeling and preserves mineral density, even in deficiency of steroid hormones in elderly individuals. ${ }^{11}$ Consequently, it can balance calcium homeostasis impaired due to estrogen deficiency and prevent the loss of mineral mass of the bones after menopause. ${ }^{12-14}$ Literature data on the systemic influence of whole-body vibration (WBV) are rather controversial and demonstrate both positive and negative features. ${ }^{15-18}$ Some parameters of vibration inhibit, while others accelerate bone remodeling. However, the permanent influence of vibration throughout reproductive life in individuals of various ages and gender has been studied incompletely. In our previous investigations, we assessed bone tissue condition under the influence of vibration with low frequency and high level of vibration acceleration in young male rats. It should be mentioned that vibration acceleration over $0.5 \mathrm{~g}$ caused severe bone damage with the loss of mineral mass even in the remote period after cessation of vibration.

The aim of this research was to establish the condition of a mineral component of the tibia and the degree of influence of the whole body vibration with acceleration level $0.3 \mathrm{~g}$, frequency $50 \mathrm{~Hz}$ on remodeling process in young and pubescent rats after menopause modeling. An experimental investigation was 
conducted on 2-month-old rats. This experimental model was performed in order to establish differences in the ratio of a mineral component and amorphous substance, represented by collagen, between control and experimental groups.

\section{Materials and methods}

\section{Animal model}

The experimental study was performed on 54 male 2-month-old Wistar rats weighing 180-200 g. All animal experiments were conducted in compliance with bioethical principles per the provisions of the European Convention for the Protection of Vertebrate Animals used for Experimental and Other Scientific Purposes. The experimental rats were divided into 3 groups, 18 rats in each: control group - SHAM surgery (SHAMsurg), I experimental group - ovariectomized rats (OVE), II experimental group - ovariectomized rats + whole-body vibration $(\mathrm{OVE}+\mathrm{WBV})$. All experimental rats were weighed every two weeks (Figure 1a). After the $8^{\text {th }}$, the $16^{\text {th }}$ and the $24^{\text {th }}$ week, six animals from each group were removed from the experiment by decapitation under general intraperitoneal anesthesia at $0.3 \mathrm{~g} / \mathrm{kg}$.

\section{Whole-body vibration}

Vertical vibration oscillations were modeled using a $250 \mathrm{~W}$ APC Rain-60 vibration pump with the maximum pressure of 7 bar and a voltage regulator of the AFC-120 model. A vibrating platform with the container, where the experimental group of rats was placed, was attached to the stem of the vibrating pump. In all cases, it was equal to $1.2 \mathrm{~mm}$. The level of vibration

(a)

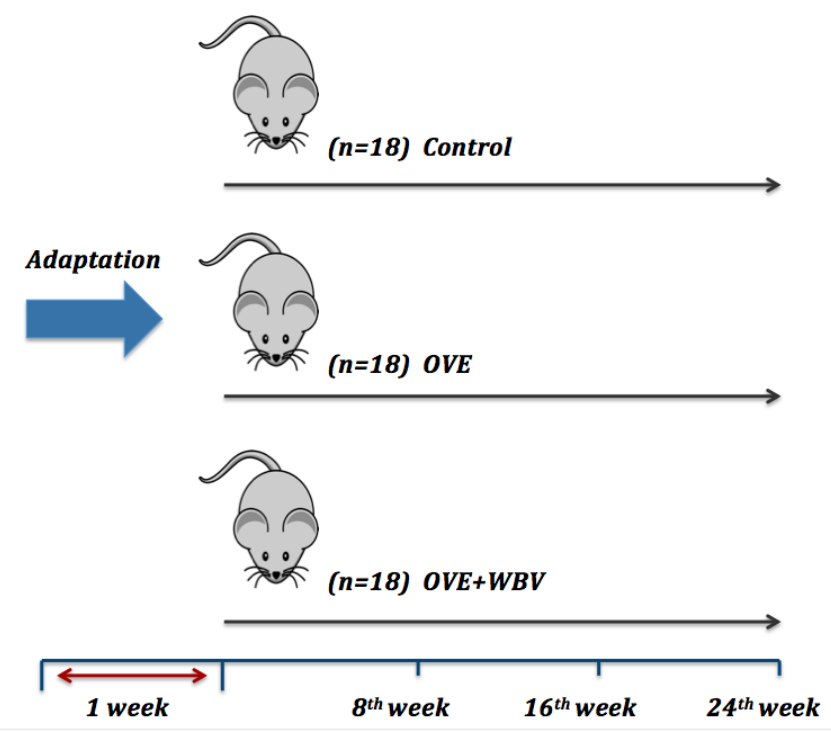

acceleration was the following: $3.0 \mathrm{~m} / \mathrm{s}^{2}-0.3 \mathrm{~g}$. The rats were exposed to WBV for 30 minutes, 5 days per week, for 24 weeks.

\section{Method of ovariectomy of the rats}

The animal was fixed in the dorsal recumbent position. Before the surgery, $1 \mathrm{ml}$ of $10 \%$ glucose solution was administered to prevent hypoglycemia. We used $0.3 \mathrm{~g} / \mathrm{kg}$ of urethane solution for general intraperitoneal anesthesia (Figure 1b). One day after the laparotomy with ovariectomy, animals had a standard diet and were kept separately in individual plastic cages for seven days.

\section{Determining the hormone concentration}

To assess bone metabolism in rat blood plasma, we determined the levels of parathyroid hormone and calcitonin using commercial EIA DRG-3645 PTH (Parathyroid hormone) Intact ELISA and EIA DRG-3648 Calcitonin ELISA (DRG International, Inc., USA). The study is based on the "sandwich" method (double-antibody method). Standards, controls, test samples and specific antibodies to the corresponding hormone labeled with biotin are added to the wells coated with PTH/CT antibodies. This forms AB-PTH/CT-AB+Biotine complex. After the first incubation and washing phase, a chromogenic solution (tetramethylbenzidine) is added. The intensity of its color changes in direct proportion to the concentration of the sample's specific antibodies. We measured the color intensity at a wavelength of $450 \mathrm{~nm}$.

(b)

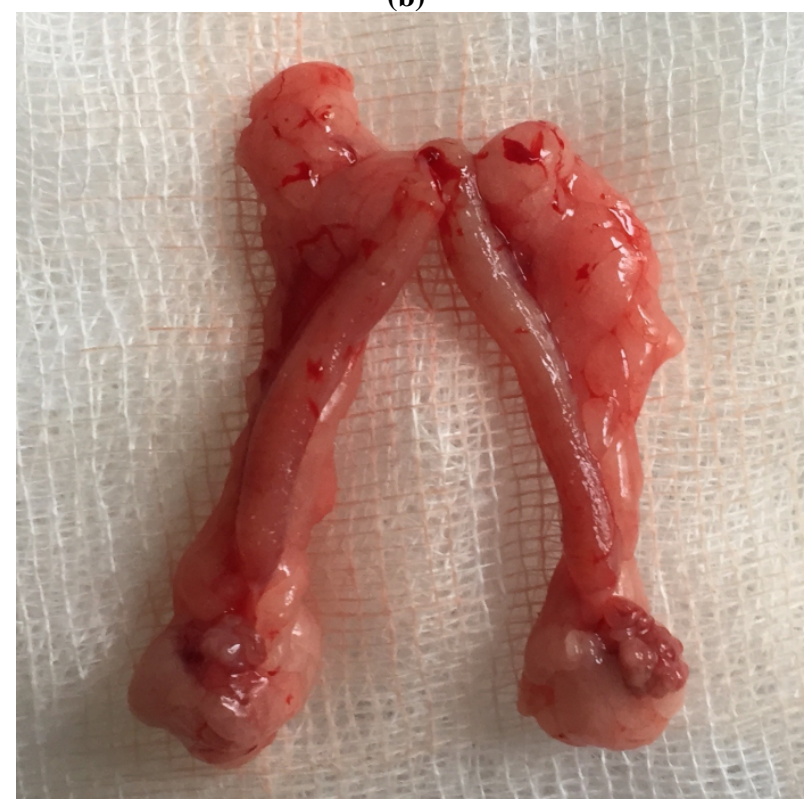

Figure 1. (a) - Experimental design. (b) - Preparation of the removed ovaries with uterine horns. 


\section{X-ray diffraction}

To study the ultrastructure of the tibia bone mineral component we used the method of X-ray diffraction analysis. ${ }^{19-23}$ The tibia was dried at $110^{\circ} \mathrm{C}$ in a drying cabinet. The $\mathrm{X}$-ray diffraction spectra of the samples were obtained on an automated X-ray diffractometer in $\mathrm{Cu} \mathrm{K} \alpha$ radiation $(\lambda=1.5418 \AA)$, monochromatized by reflection from a plane (002) of a single pyrographite crystal, mounted on a diffracted beam. We used the Bragg-Brentano focusing scheme $(\theta-2 \theta)$. The diffraction patterns were recorded in the continuous movement mode of the detector with an angular velocity of $2 \% \mathrm{~min}$, a constant value of the integration time $\tau=1 \mathrm{~s}, \mathrm{x}$-ray tube voltage at $\mathrm{U}=26 \mathrm{kV}$, and anode current at $\mathrm{I}=15 \mathrm{~mA}$.

\section{Statistical analysis}

Statistical analysis of the data was performed in StatSoft STATISTICA 8.0.360. In the STATISTICA package, the comparison of two average samples of normally distributed features (Student's t-criterion) was implemented in the Basic Statistics/Tables module. The t-test, independent, by variable submodule, was used for two different general summations. One-way ANOVA is implemented in the Breakdown \& one-way ANOVA submenu of the Basic Statistics and Tables module.

\section{Results}

The weight of laboratory rats in I group (OVE) increased to $308.0 \pm 8.6 \mathrm{~g}$ in the $24^{\text {th }}$ week, and in rats OVE+WBV group to $274.2 \pm 5.1 \mathrm{~g}$, respectively. A slight decrease in PTH level was observed on the $8^{\text {th }}$ week of the investigation in both experimental groups, however, it was statistically insignificant. It should be mentioned that in the I experimental group, PTH level was increasing against group OVE+WBV, while in the second experimental group the hormone index remained without statistically significant changes against control. Calcitonin level also did not vary statistically in the second experimental group (OVE+WBV), however, a reliable increase in hormone concentration in the I experimental group (OVE) was recorded on the $16^{\text {th }}$ day of the experiment $(\mathrm{p}<0.05)$ and during $24^{\text {th }}$ week $(p<0.05)$. One-way analysis of variance showed statistically reliable standard deviations of $\mathrm{F}$ criterion for calcitonin $-\mathrm{Ca} / \mathrm{P}$ $(p<0.01)$ on the $16^{\text {th }}-24^{\text {th }}$ week of the investigation in the first experimental group; similar dependence was also observed for PTH - Ca/P $(p<0.01)$. WBV resulted in stabilization of the indices, likely inhibiting prior stimulated remodeling of bone tissue (Table 1).

While assessing bone remodeling mechanisms, it is important to evaluate the amorphous phase, which is represented mainly by collagen, since it is layered with hydroxyapatite. This process is necessary to understand the mechanisms of bone mineral loss. To determine the contents of the amorphous phase, which is manifested by the presence of diffuse halo at small scattering angles, the scattering angles $2 \theta=15-37.5^{\circ}$ were decomposed into separate maxima corresponding to the scattering by the amorphous and crystalline phases. The background diffraction patterns in this range of scattering angles were approximated by a linear function. The volume fraction of the crystalline phase represented by hydroxyapatite was determined through the following formula: $\mathbf{X}=\mathbf{I a} / \mathbf{I}$, where Ia is the integral intensity of hydroxyapatite, and I is the total integral intensity. The average crystallite size was determined by the Debye-Scherrer formula per the diffraction maximum (002) extension: $\mathbf{L}=\lambda /(\boldsymbol{\beta} \cos (\boldsymbol{\theta}))$, where $\lambda=0.15148 \mathrm{~nm}$ is the wavelength of the $\mathrm{X}$-ray radiation, $\beta$ is the physical half-width of the maximum (002), $2 \theta$ is the reflection diffraction angle (002) of the crystalline phase,

Figure 2.

Table 1. Quantitave analysis of bone remodeling markers

\begin{tabular}{|c|c|c|c|c|c|c|c|}
\hline \multirow{3}{*}{$\begin{array}{l}\text { Bone remodel. } \\
\text { markers }\end{array}$} & \multirow{3}{*}{ Group } & \multicolumn{6}{|c|}{ Weeks after surgery } \\
\hline & & \multicolumn{2}{|c|}{8} & \multicolumn{2}{|c|}{16} & \multicolumn{2}{|c|}{24} \\
\hline & & Mean \pm SEM & SD & Mean \pm SEM & SD & Mean \pm SEM & SD \\
\hline \multirow{3}{*}{$\begin{array}{l}\text { PTH, } \\
\mathrm{ng} / \mathrm{ml}\end{array}$} & SHAMsurg & $34.1 \pm 2.5$ & 5.5 & $31.5 \pm 3.1$ & 6.9 & $36.4 \pm 3.4$ & 7.6 \\
\hline & OVE & $32.8 \pm 3.9$ & 8.7 & $38.3 \pm 2.8$ & 6.8 & $43.2 \pm 3.1$ & 7.0 \\
\hline & $O V E+W B V$ & $31.7 \pm 2.3$ & 5.2 & $33.0 \pm 2.3$ & 5.2 & $37.5 \pm 1.9$ & 4.3 \\
\hline \multirow{3}{*}{$\begin{array}{l}\text { Calcitonin, } \\
\mathrm{ng} / \mathrm{ml}\end{array}$} & SHAMsurg & $10.25 \pm 0.99$ & 2.2 & $8.1 \pm 1.2$ & 2.8 & $7.9 \pm 1.1$ & 2.6 \\
\hline & $O V E$ & $8.8 \pm 1.6$ & 3.7 & $12.5 \pm 1.5 *$ & 3.4 & $13.4 \pm 1.6 *$ & 3.6 \\
\hline & $O V E+W B V$ & $10.4 \pm 1.1$ & 2.4 & $9.91 \pm 0.5$ & 2.0 & $11.1 \pm 1.3$ & 2.9 \\
\hline \multirow{3}{*}{$\begin{array}{c}\mathrm{Ca}, \\
\mathrm{mmol} / 1\end{array}$} & SHAMsurg & $2.23 \pm 0.13$ & 0.28 & $2.27 \pm 0.14$ & 0.32 & $2.52 \pm 0.12$ & 0.27 \\
\hline & OVE & $2.28 \pm 0.12$ & 0.27 & $2.19 \pm 0.13$ & 0.29 & $2.62 \pm 0.15$ & 0.34 \\
\hline & $O V E+W B V$ & $2.17 \pm 0.13$ & 0.30 & $2.18 \pm 0.12$ & 0.26 & $2.48 \pm 0.14$ & 0.30 \\
\hline \multirow{3}{*}{$\begin{array}{c}\mathrm{P}, \\
\mathrm{mmol} / 1\end{array}$} & SHAMsurg & $1.61 \pm 0.12$ & 0.27 & $1.51 \pm 0.17$ & 0.37 & $1.39 \pm 0.13$ & 0.28 \\
\hline & $O V E$ & $1.1 \pm 0.13 *$ & 0.28 & $1.18 \pm 0.08 *$ & 0.17 & $1.41 \pm 0.12$ & 0.28 \\
\hline & $O V E+W B V$ & $1.39 \pm 0.13$ & 0.28 & $1.30 \pm 0.10$ & 0.23 & $1.33 \pm 0.10$ & 0.23 \\
\hline
\end{tabular}

* - groups differ statistically $p<0.05$ 
(a)

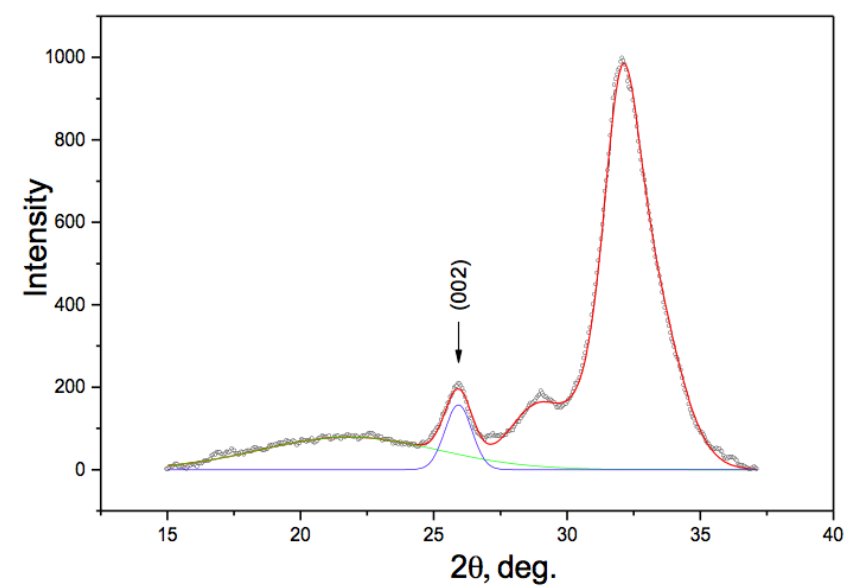

(b)

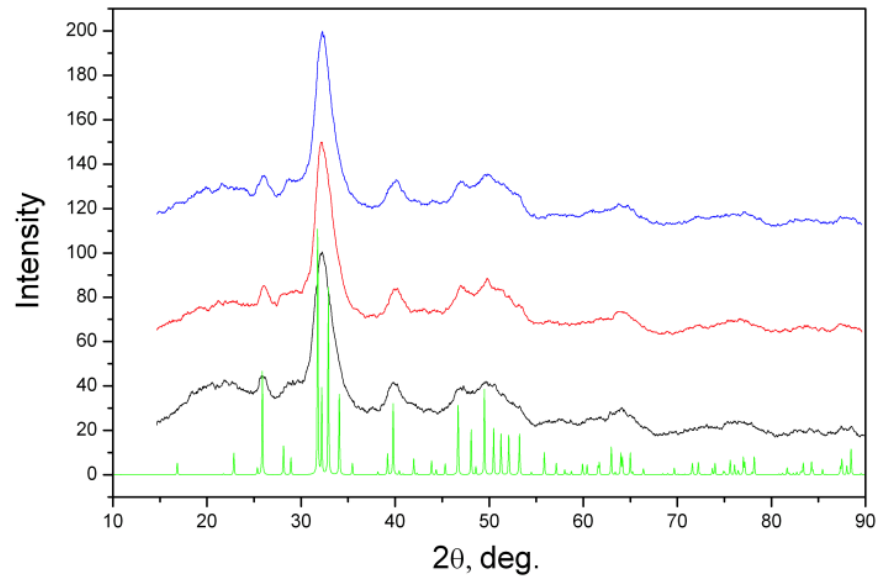

Figure 2. A - The diffractogram is presented as a superposition of maximums: dots - experimental data, red line - approximate curve, blue line - profile of maximum (002) of a crystalline phase, green line - profile of maximum of amorphous phase. B - The diffraction spectra of the samples were obtained on an automated $\mathrm{X}$-ray diffractometer in $\mathrm{Cu} \mathrm{K \alpha}$ radiation by monochromatic reflection from the plane (002) of a single graphite crystal mounted on a diffracted beam. The spectra were recorded in the continuous moving mode of the detector at the 2 $\mathrm{deg} / \mathrm{min}$ speed. To determine the integral intensity of the hydroxyapatite reflex, we chose a reflex in $30-37^{\circ}$ angular range since its intensity is the highest. Although this reflex consists of four reflexes of hydroxyapatite with Miller indices (211); (112); (300); (202), the diffraction angles from crystallographic planes with these indices are close to $31.741^{\circ} ; 32.179^{\circ} ; 32.868^{\circ}$ and $34.045^{\circ}$.

(a)

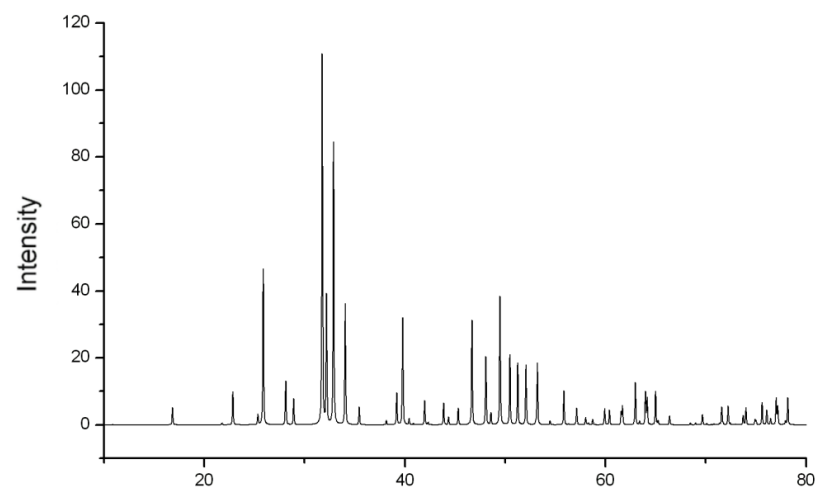

(c)

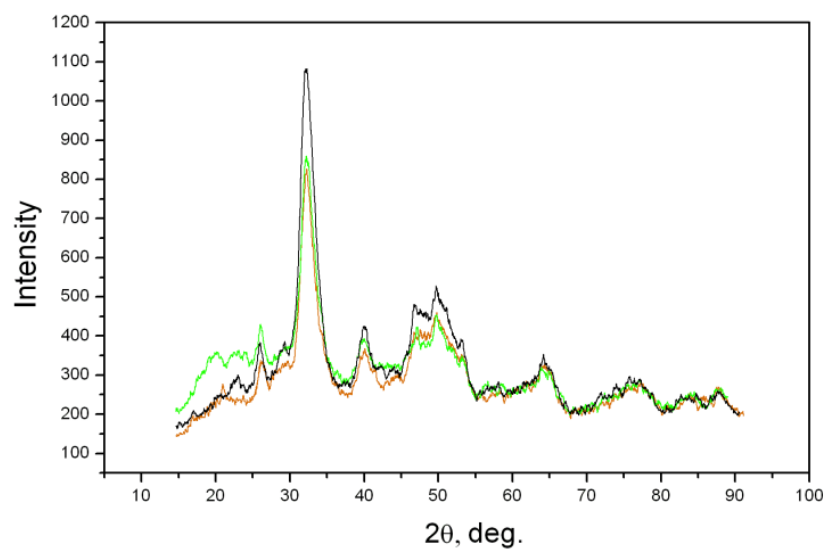

(b)

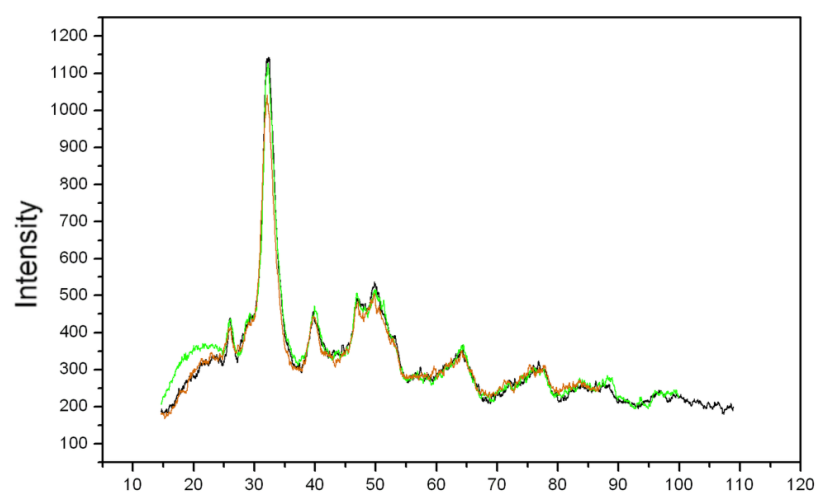

(d)

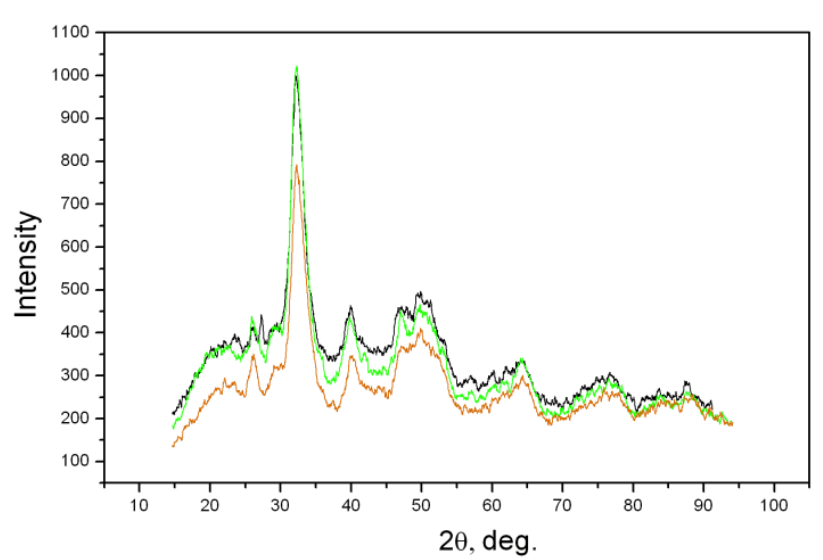

Figure 3. A - X-ray diffraction patterns of hydroxyapatite, B - SHAM-surgery group; C - I-group (OVE); D - II-group (OVE+WBV). $\square 8^{\text {th }}$ week; $\square 16^{\text {th }}$ week $\square 24^{\text {th }}$ week. 
Table 2. Structural parameters of tibia samples

\begin{tabular}{|c|c|c|c|c|}
\hline Group/week & $\mathbf{X}_{\mathrm{am}}$ & $\mathbf{X}_{\text {cr }}$ & $\mathbf{B}_{(002)}{ }^{\circ}$ & $\mathbf{L}, \mathbf{n m}$ \\
\hline Control $8^{\text {th }}$ week & 0.129 & 0.871 & $1.017 \pm 0.031$ & $13.9 \pm 0.7$ \\
\hline Control $16^{\text {th }}$ week & 0.132 & 0.868 & $1.047 \pm 0.040$ & $13.2 \pm 0.8$ \\
\hline Control $24^{\text {th }}$ week & 0.228 & 0.772 & $1.007 \pm 0.035$ & $14.1 \pm 0.8$ \\
\hline OVE $8^{\text {th }}$ week & $0.123 *$ & 0.877 & $1.031 \pm 0.026$ & $13.6 \pm 0.5$ \\
\hline OVE $16^{\text {th }}$ week & $0.187 *$ & 0.813 & $1.046 \pm 0.033$ & $13.3 \pm 0.7$ \\
\hline OVE $24^{\text {th }}$ week & $0.125 *$ & 0.875 & $0.988 \pm 0.039$ & $14.5 \pm 0.9$ \\
\hline$O V E+W B V 8^{\text {th }}$ week & $0.179 *$ & 0.821 & $1.077 \pm 0.052$ & $12.7 \pm 0.9$ \\
\hline$O V E+W B V 1 \sigma^{\text {th }}$ week & $0.165 *$ & 0.835 & $0.956 \pm 0.064$ & $15.3 \pm 1.7$ \\
\hline$O V E+W B V 24^{\text {th }}$ week & 0.188 & 0.812 & $1.718 \pm 0.090$ & $6.6 \pm 0.4$ \\
\hline
\end{tabular}

* - groups differ statistically $p<0.05$;

$X_{c r}$ - the volume fraction of the crystalline phase;

$X_{a m}$ - the volume fraction of the amorphous phase;

$B_{(002)}$ - the half-width of the maximum (002) of the $\mathrm{Ca}_{10} \mathrm{P}_{6} \mathrm{O}_{26} \mathrm{H}_{2}$ phase;

$L$ - the average crystallite size of the $\mathrm{Ca}_{10} \mathrm{P}_{6} \mathrm{O}_{26} \mathrm{H}_{2}$ phase.

The results of calculations of crystalline phase in bone tissue of a rat tibia are presented in Figure 3 and Table 2. As it is seen from the image on spectra, the volume of the crystalline phase slightly increases in rats of the control group on the 8 th week $\rightarrow$ 16 th week $\rightarrow 24$ th week. In the OVE group, a reliable decrease in the absolute amount of hydroxyapatite is observed on the 8th16 th week, and stabilization of this process is recorded already on the 24th week compared with the control group. WBV prevented early bone loss after ovariectomy on the 8th-16th week. Ovariectomized rats under the influence of vibration showed statistically higher $(\mathrm{p}<0.05)$ values of crystalline phase compared with indices in the control group during the same period. Although vibration had a positive impact on bone tissue in rats after ovariectomy on the 8th-16th week, this influence was not statistically reliable on the 24 th week.

\section{Discussion}

In our experimental model, acceleration levels $0.3 \mathrm{~g}$ were used, which is within registered safe levels (ISO 2631-1, 1997; ISO 5349-1, 2001). However, such values of vibration acceleration, but with low frequency, can occur in manufacturing, and longlasting exposure can result in the development of severe damage to bone tissue with further clinical manifestations. It should be taken into consideration while choosing vibration parameters. The document states that lower frequencies, especially in the low-frequency range of $10-20 \mathrm{~Hz}$, can lead to multiple amplification of input vibration due to the resonance phenomenon. The tibia was chosen due to anatomical peculiarities of contact points with a vibration platform. In other parts of the skeleton, vibration oscillations weaken, bypassing major joints and massive muscular tissue of the femur. The research was limited to a 6-month period, since it is sufficient for duration of 4-6 cycles of bone remodeling in a rat. The age of rats reached the time when normal loss of bone mineral composition occurred, which is associated not only with menopause, but also with the aging process. In the control group, mineral mass slightly altered throughout the entire period of the experiment.
Estrogen deficiency after ovariectomy or menopause in women is known to accelerate bone remodeling with further loss of mineral density in bone tissue, which is frequently a cause of pathological fractures. In rats, ovariectomy also leads to an increase in the rate of bone resorption and osteoporosis. ${ }^{24-27}$ Concentrations of calcitonin and parathyroid hormone in blood serum are rarer used for assessment of bone tissue remodeling than protein markers; ${ }^{28-29}$ however, they are rather informative for calcium-phosphate metabolism. ${ }^{30-36}$ In our experiment, we observed an increase in calcitonin level in ovariectomized rats, since calcitonin inhibits bone resorption, and its elevation may explain mineral mass loss after ovariectomy. We showed that calcium level was lower in ovariectomized rats than in the control group already in 8-16 weeks after surgery, though this index was statistically insignificant. The cause of this difference is not completely understood; slight hypocalcaemia in rats after OVE probably induced compensatory secretion of PTH, which is known to increase differentiation of osteoclasts and osteoblasts in rats (inhibits remodeling). Within 8-16 weeks, such modifications were observed in the group OVE+WBV. In the first experimental group (OVE), PTH concentration increased, whereas the further influence of WBV returns its level to the values present before surgery, thus, as in the control group. Data concerning the impact of estrogen deficiency on this parameter are ambiguous. Although calcium level in rat blood serum did not change reliably throughout the entire period, phosphorus level reliably decreased in group I and, slightly, in group II. Besides, a considerable decrease in phosphorus was observed in ovariectomized rats already in eight weeks after surgery.

Nevertheless, only investigation of hormones is not sufficient for assessment of mineral component loss. Thus, we estimated structure, organization and features of structural bone components ranging from microstructure to nanocomposites. To assess bone microstructure and nanocomposites, we conducted invasive examination - XRD, which enables to determine basic components - collagen and hydroxyapatites. In addition to the investigation of the nature of the bone mineral phase, this investigation played an important role in the interpretation of the structure of the main protein component of the bone - collagen. 
The diffractogram of pure hydroxyapatite samples and bone minerals are compared in Figure 3. Different peaks represent diffraction from crystal lattices. Results of X-ray diffraction in an investigation of bone nanostructure are presented in Table 2. The perspective of our future research will be the task to investigate and characterize the structure, deformation of mineral component and collagen fibers under conditions of excessive mechanical load and fractures.

The combination of two different components in the bone, elastic fibrous protein and fragile mineral phase, results in obtaining very strong material. It is important for the understanding of fracture mechanisms. It has become evident that only the density of mineral bone does not determine bone strength in general. ${ }^{1,2,93,94}$ In addition to mineral density, there are other characteristics, associated with mineral crystals, including their form, size, perfection, orientation, etc., which can have a direct impact on the mechanical properties of bone tissue. Information on the basic structural unit of the bone - mineralcollagen composite - will provide a better understanding of the general pattern and fragility of the tissue. Thus, X-ray diffraction proved an efficient technique for the investigation of structural and mechanical characteristics of bone mineral and the presentation of reliable experimental data.

\section{Conclusion}

Whole-body vibration $(0.3 \mathrm{~g})$ can significantly influence the absolute amount of mineral component in the tibia, confirmed by the XRD method. Such vibration oscillations do not cause severe micro damage. The most significant indices of mineral component loss were observed in ovariectomized rats on the $8^{\text {th }}$ $16^{\text {th }}$ week of the experiment in the first experimental group. Vibration with acceleration level $0.3 \mathrm{~g}$ prevented loss of mineral component. However, vibration oscillations proved ineffective during the $24^{\text {th }}$ week of the experiment, i.e. in old rats. An increase in the tibia mineralization due to vibration was not recorded in the second experimental group, but only retardation of mineral component loss, starting from the eighth week, was observed.

\section{Funding}

This work was supported by the Department of Normal Physiology of Danylo Halytsky Lviv National Medical University "Researching the role of systemic and paracrine regulatory mechanisms in providing homeostasis of functional and metabolic parameters of the organism under conditions of adaptation to extreme factors of diverse nature" (state registration number $0116 \mathrm{U} 004510$ ).

\section{Ethics approval and consent to participate}

Ethics Commission Report №10, 16.12.2019, Danylo Halytsky Lviv National Medical University

\section{Abbreviations}

OVE - ovariectomy, PTH - parathyroid hormone, WBV whole body vibration

\section{References}

1. Akkawi I, Zmerly H. Osteoporosis: current concepts. Joints. 2018;6(2):122-127. https://doi.org/10.1055/s-0038-1660790

2. Cao JJ. Effects of obesity on bone metabolism. Journal of Orthopaedic Surgery and Research. 2011;6(1):30. https://doi.org/10.1186/1749-799X-6-30

3. Eastell R, O'Neill TW, Hofbauer LC, et al. Postmenopausal osteoporosis. Nature Reviews Disease Primers. 2016;2(1):1-16. https://doi.org/10.1038/nrdp.2016.69

4. Sözen T, Özışık L, Başaran NÇ. An overview and management of osteoporosis. European Journal of Rheumatology. 2017;4(1):46. https://doi.org/10.5152/eurjrheum.2016.048

5. Alswat KA. Gender disparities in osteoporosis. Journal of Clinical Medicine Research. 2017;9(5):382. https://doi.org/10.14740/jocmr2970w

6. Hammad LF, Benajiba N. Lifestyle factors influencing bone health in young adult women in Saudi Arabia. African Health Sciences. 2017;17(2):524-531. https://doi.org/10.4314/ahs.v17i2.28

7. Langdahl BL. Osteoporosis in premenopausal women. Current Opinion in Rheumatology. 2017;29(4):410-415. https://doi.org/10.1097/BOR.0000000000000400

8. Lam TP, Ng BKW, Cheung LWH, et al. Effect of whole body vibration (WBV) therapy on bone density and bone quality in osteopenic girls with adolescent idiopathic scoliosis: a randomized, controlled trial. Osteoporosis International. 2013;24(5):16231636. https://doi.org/10.1007/s00198-012-2144-1

9. Pang MY, Lau RW, Yip SP. The effects of whole-body vibration therapy on bone turnover, muscle strength, motor function, and spasticity in chronic stroke: a randomized controlled trial. European Journal of Physical and Rehabilitation Medicine. 2013;49(4):439-450.

10. McGee-Lawrence ME, Wenger KH, Misra S, et al. Whole-body vibration mimics the metabolic effects of exercise in male leptin receptor-deficient mice. Endocrinology. 2017;158(5):1160-1171. https://doi.org/10.1210/en.2016-1250 
11. Minematsu A, Nishii Y, Imagita H, Sakata S. Whole body vibration at low-frequency can increase trabecular thickness and width in adult rats. Journal of Musculoskeletal \& Neuronal Interactions. 2019;19(2):169.

12. Huang CC, Tseng TL, Huang WC, et al. Whole-body vibration training effect on physical performance and obesity in mice. International Journal of Medical Sciences. 2014;11(12):1218. https://doi.org/10.7150/ijms.9975

13. Bellia A, Salli M, Lombardo M, et al. Effects of whole body vibration plus diet on insulin-resistance in middle-aged obese subjects. International Journal of Sports Medicine. 2014;35(06):511-516. https://doi.org/10.1055/s-0033-1354358

14. Maddalozzo GF, Iwaniec UT, Turner RT, et al. Whole-body vibration slows the acquisition of fat in mature female rats. International Journal of Obesity. 2008;32(9):1348. https://doi.org/10.1038/ijo.2008.111

15. Cvetkovic MM, Baptista JS, Vaz MP. Occupational vibration in urban bus and influence on driver's lower limbs: a review. U. Porto Journal of Engineering. 2018;4(1):56-66. https://doi.org/10.24840/2183-6493_004.001_0005

16. Bovenzi M, Schust M, Mauro M. An overview of low back pain and occupational exposures to whole-body vibration and mechanical shocks. Med Lav. 2017;108(6):419-433. https://doi.org/10.23749/mdl.v108i6.6639

17. Kostyshyn N, Grzegotsky M, Servetnyk M. Assessment of structural and functional condition of rats bone tissue under the influence of various parameters of vibration. Current Issues in Pharmacy and Medical Sciences. 2018;31(3):148-153. https://doi.org/10.1515/cipms-2018-0029

18. Kostyshyn NM, Kostyshyn LP, Servetnyk MI, Grzegotsky MR. The Peculiarities of Remodelling Muscle Tissue of Rats Under the Vibration Influence. Prilozi. 2019;40(1):59-65. https://doi.org/10.2478/prilozi-2019-0004

19. Clark SM, Iball J. The X-ray crystal analysis of bone. Progress in Biophysics and Biophysical Chemistry: Progress Series. 2016;7:226. https://doi.org/10.1016/S0096-4174(18)30127-6

20. Bunaciu AA, UdriŞTioiu EG, Aboul-Enein HY. X-ray diffraction: instrumentation and applications. Critical Reviews in Analytical Chemistry. 2015;45(4):289-299. https://doi.org/10.1080/10408347.2014.949616

21. Rogers KD, Daniels P. An X-ray diffraction study of the effects of heat treatment on bone mineral microstructure. Biomaterials. 2002;23(12):2577-2585. https://doi.org/10.1016/S0142-9612(01)00395-7

22. Piga G, Solinas G, Thompson TJU, et al. Is X-ray diffraction able to distinguish between animal and human bones? Journal of Archaeological Science. 2013;40(1):778-785. https://doi.org/10.1016/j.jas.2012.07.004

23. Tadano S, Giri B. X-ray diffraction as a promising tool to characterize bone nanocomposites. Science and Technology of Advanced Materials. 2012;12(6):064708. https://doi.org/10.1088/1468-6996/12/6/064708

24. Compston JE. Sex steroids and bone. Physiological reviews. 2001;81(1):419-447. https://doi.org/10.1152/physrev.2001.81.1.419

25. Manolagas SC, Kousteni S, Jilka RL. Sex steroids and bone. Recent Progress in Hormone Research. 2002;57:385-410. https://doi.org/10.1210/rp.57.1.385

26. Khosla S, Monroe DG. Regulation of bone metabolism by sex steroids. Cold Spring Harbor Perspectives in <edicine. 2018; 8(1): a031211. https://doi.org/10.1101/cshperspect.a031211

27. Singh-Ospina N, Maraka S, Rodriguez-Gutierrez R, et al. Effect of sex steroids on the bone health of transgender individuals: a systematic review and meta-analysis. The Journal of Clinical Endocrinology \& Metabolism. 2017;102(11):3904-3913. https://doi.org/10.1210/jc.2017-01642

28. Hlaing T.T., Compston J.E. Biochemical markers of bone turnover-uses and limitations. Annals of Clinical Biochemistry. 2014;51(2):189-202. https://doi.org/10.1177/0004563213515190

29. Morris H.A., Eastell R., Jorgensen N.R., et al. Clinical usefulness of bone turnover marker concentrations in osteoporosis. Clinica Chimica Acta. 2017;467:34-41. https://doi.org/10.1016/j.cca.2016.06.036

30. Gozdzialska A, Jaskiewicz J, Knapik-Czajka M, et al. Association of calcium and phosphate balance, vitamin D, PTH, and calcitonin in patients with adolescent idiopathic scoliosis. Spine. 2016;41(8):693-697. https://doi.org/10.1097/BRS.0000000000001286

31. Martin TJ, Sims NA. Calcitonin physiology, saved by a lysophospholipid. Journal of Bone and Mineral Research. 2015;30(2):212215. https://doi.org/10.1002/jbmr.2449

32. Felsenfeld AJ, Barton SL. Calcitonin, the forgotten hormone: does it deserve to be forgotten?. Clinical Kidney Journal. 2015;8(2):180-187. https://doi.org/10.1093/ckj/sfv011

33. Florencio-Silva R, da Silva Sasso GR, Sasso-Cerri E, et al. Biology of bone tissue: structure, function, and factors that influence bone cells. BioMed Research International. 2015:421746. https://doi.org/10.1155/2015/421746

34. Clarke MV, Russell PK, Findlay DM, et al. A role for the calcitonin receptor to limit bone loss during lactation in female mice by inhibiting osteocytic osteolysis. Endocrinology. 2015;156(9):3203-3214. https://doi.org/10.1210/en.2015-1345

35. Wysolmerski JJ. Parathyroid Hormone, Parathyroid Hormone-Related Protein, and Calcitonin. In Vitamin D. Academic Press. 2018; 849-870.

36. Klemm KM, Klein MJ. Biochemical markers of bone metabolism. Henry's Clinical Diagnosis and Management by Laboratory Methods E-Book, 2017; 188. 